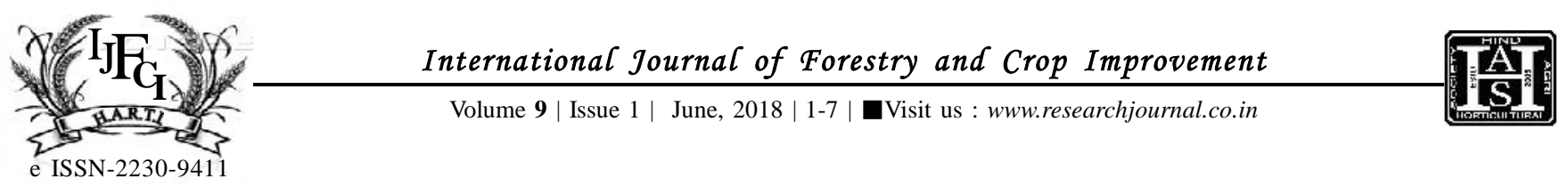

\title{
Clonal propagation technique for mass multiplication of Noni (Morinda citrifolia) seedlings
}

\author{
M. Sangareswari Nagajothi, P. R. Renganayaki, S. Sundareswaran, B. Palanikumaran and M. Umamahesvari
}

\begin{abstract}
A study was under taken to standardize the type of cutting, concentration of growth hormone and suitable rooting media to produce elite seedlings in Morinda citrifolia at Forest College and Research Institute, Mettupalayam. Investigation was carried out to standardize the treatments to induce root and shoot growth in different types of cuttings of Morinda citrifolia $\mathrm{L}$. using two growth regulators (IAA, IBA) used in different concentrations $(1000,1500,2000$ and $2500 \mathrm{ppm})$ in two kinds growth medium (Sand and Coir) for different type of cuttings, $2500 \mathrm{ppm}$ IBA treatment recorded its superiority in terms of maximum sprouting (85\%), rooting (79\%) and survival (70\%) percentage, number of roots (15.83), root length $(8.51 \mathrm{~cm})$, number of shoots (4.00) and shoot length $(9.43 \mathrm{~cm})$ in leafy shoot cuttings, irrespective of rooting media used. From this current study it is concluded that, for macro clonal propagation of noni (Morinda citrifolia L.), either leafy shoot cuttings or hard wood cuttings could be treated with 2500 ppm IBA or semi hard wood cuttings could be treated with 1500 ppm IAA and could be planted in coir pith medium for the production of elite planting materials.
\end{abstract}

KEY WORDS : Noni, Macro clonal, Cuttings, Growth regulators, Growth medium

How TO CITE THIS ARTICLE : Nagajothi, M. Sangareswari, Renganayaki, P.R., Sundareswaran, S., Palanikumaran, B. and Umamahesvari, M. (2018). Clonal propagation technique for mass multiplication of Noni (Morinda citrifolia) seedlings. Internat. J. Forestry \& Crop Improv., 9(1) : 1-7, DOI: 10.15740/HAS/IJFCI/9.1/1-7. Copyright@ 2018: Hind Agri-Horticultural Society.

Article ChroniCAL : Received : 04.01.2018; Revised : 11.05.2018; Accepted : 21.05.2018 